\title{
PENSAR FUERA DEL MARCO: MARÍA CAMPO ALANGE, CRÍTICA DE ARTE PROTOFEMINISTA*
}

\author{
PATRICIA MAYAYO ${ }^{1}$ \\ Universidad Autónoma de Madrid
}

\begin{abstract}
Este artículo explora el trabajo de María Campo Alange (1902-1986) como crítica de arte. Sus escritos han sido casi totalmente ignorados en la literatura académica, quizá porque no encajan dentro de los tópicos habituales en la crítica artística española de la época. Según veremos, este "pensar fuera del marco" no solo tiene que ver con la singularidad de la trayectoria de Campo Alange, sino también con la fragilidad de su posición como mujer intelectual en el contexto del régimen franquista, que proscribía la participación de las mujeres en la esfera pública. Mantenerse alejada de los "grandes debates" de su tiempo era una forma de labrarse un espacio de libertad, así como de iluminar un punto ciego que los críticos hegemónicos no fueron capaces de abordar: el lugar de las mujeres dentro del arte moderno.
\end{abstract}

Palabras clave: Campo Alange; crítica de arte en España; franquismo; crítica de arte feminista.

\section{THINKING OUTSIDE THE FRAME OF FRANCOISM: MARÍA CAMPO ALANGE AS} A FEMINIST ART CRITIC

This article explores María Campo Alange's (1902-1986) work as an art critic. Her writings have been mostly ignored in scholarly literature, perhaps because they do not conform to the dominant trends of Spanish art criticism of her time. Such a marginal position, I contend, was related to Campo Alange's unique personality, but also to her precarious situation as a woman intellectual within the context of Francoism, which banned women from participating in the public sphere. Distancing herself from the "trending topics" of the time allowed her to find her own space and to identify a blind spot in the mainstream narrative of Spanish art criticism: the contribution of women artists to modern art.

Key words: Campo Alange; Art Criticism in Spain; Francoism; Feminist art criticism.

Cómo citar este artículo / Citation: Mayayo, Patricia (2021) "Pensar fuera del marco: María Campo Alange, crítica de arte protofeminista". En: Archivo Español de Arte, vol. 94, núm. 374, Madrid, pp. 133-142 https://doi.org/10.3989/aearte.2021.08

María Campo Alange (1902-1986)² es un personaje difícil de clasificar: próxima, al mismo tiempo, al crítico de arte franquista Eugenio d'Ors y al enemigo declarado de este, el liberal

\footnotetext{
* Trabajo realizado en el marco del Proyecto I+D "Los públicos del arte y la cultura visual contemporánea en España”, PID2019-105800GB-I00, IPs: Noemi de Haro García y Patricia Mayayo.

${ }^{1}$ patricia.mayayo@uam.es / ORCID iD: https://orcid.org/0000-0001-9687-5423

2 María Campo Alange (nacida María Laffitte) firmó todas sus obras con el apellido de su marido. Como ella misma narra en su autobiografía (Campo Alange, 1983: 68), al publicar su segundo libro, quiso que llevase en la portada su nombre de soltera, pero la editorial solo aceptó proseguir con la publicación a condición de que lo firmara como Condesa de Campo Alange. Por esta razón, algunas investigadoras han optado por usar el nombre de María Laffitte para designar a esta autora. Considero, no obstante, que la marca distintiva de una escritora es el nombre con el que firma sus libros: de ahí que me haya inclinado en este artículo por hablar de María Campo Alange, que es el nom de plume que la autora adoptó a finales de los años sesenta, a raíz de su implicación creciente en el movimiento feminista.
} 
José Ortega y Gasset; aristócrata bien conectada con los círculos de poder e intelectual hecha a sí misma; excesivamente radical para las afines a la organización falangista Sección Femenina y demasiado conservadora para las feministas jóvenes que protagonizarán la Segunda Ola... Parte de esta imposibilidad de encasillar a Campo Alange tiene que ver con el carácter polifacético de su trayectoria. Nacida en Sevilla en 1902 en el seno de una familia de industriales adinerados, a los veinte años contrae matrimonio con José Salamanca, Conde de Campo Alange. Como muchas mujeres de esa época, no tuvo oportunidad de seguir estudios universitarios y su formación fue autodidacta. En 1931, huyendo de la República, se instaló junto a su marido en París, donde comenzó a estudiar pintura en un taller de Montparnasse y descubrió la obra de María Blanchard. La fascinación que le produjo la pintora santanderina, y el arte de vanguardia en general, supuso un punto de inflexión fundamental en su vida: después de volver a España, publicó -a los cuarenta y dos años- su primer libro, una biografía de María Blanchard [fig. 1] que marcaría el inicio de una prolífica y heterodoxa carrera intelectual ${ }^{3}$.

Además de cultivar, de forma ocasional, la creación literaria (escribió dos libros memorias y un volumen de cuentos ${ }^{4}$ ), Campo Alange destacó en tres campos de trabajo aparentemente muy alejados: la crítica de arte, la divulgación científica y el feminismo, que es probablemente su faceta más conocida. En 1948 publicó, con notable repercusión, La secreta guerra de los sexos [fig. 2], a la que le seguirían La mujer en España. Cien años de su historia (1964) o Concepción Arenal (1820-1893), Estudio biográfico documental (1973), entre otros trabajos ${ }^{5}$. En el terreno de la ciencia, su fe en el progreso y la objetividad - algo ingenua desde el punto de vista actual- le llevó a convertirse en una firme defensora de las teorías evolucionistas y, en particular, de los escritos del paleontólogo francés Pierre Teilhard de Chardin: en su etapa como Vicepresidenta del Ateneo de Madrid, entre 1962 y 1968, organizó dos ciclos de seminarios sobre "La naturaleza evolutiva del hombre" y, a mediados de esa misma década, fundó el Grupo Español de Trabajo Teilhard de Chardin, a imagen del que ya existía en París.

Finalmente, en el campo de la crítica, hay que destacar que Campo Alange formó parte de la Academia Breve de Crítica de Arte (ABCA) hasta la muerte de su fundador, Eugenio d'Ors, en 1953, aunque la relación entre ambos se enfrió a raíz de la publicación de La secreta guerra de los sexos, que el crítico catalán recibió con manifiesta hostilidad ${ }^{6}$. Además de esta vinculación con la ABCA, Campo Alange desarrolló una extensa actividad como crítica de arte "independiente": prologó catálogos, impulsó la organización de exposiciones de mujeres artistas y participó en innumerables coloquios y conferencias sobre arte de vanguardia, además de escribir varios artículos y ensayos.

En este artículo, me gustaría profundizar en las aportaciones de la autora al ámbito de la crítica artística, que han sido muy ignoradas en la literatura académica sobre el tema: Manuel Sánchez Camargo, en su Historia de la Academia Breve de Crítica de Arte. Homenaje a Eugenio d'Ors, enumera de forma sucinta algunas de sus contribuciones a las actividades de la ABCA, destacando sobre todo su papel de introductora de la obra de María Blanchard, un aspecto que menciona, asimismo, muy brevemente, Juan Antonio Gaya Nuño en su Historia de la crítica de arte en España ${ }^{7}$. De igual modo, Paula Barreiro, en su estudio reciente Avant-garde Art and Criticism in Francoist Spain, se limita a señalar la relación de Campo Alange con el círculo d'orsiano ${ }^{8}$, mientras que Julián Díaz Sánchez y Ángel Llorente no mencionan su nombre (ni el de ninguna otra mujer, por cierto) en su gran compilación de textos de crítica de arte en España publicada en 20049.

\footnotetext{
3 Campo Alange, 1944.

${ }^{4}$ Campo Alange, 1957; 1959; 1983.

5 Campo Alange, 1948; 1964; 1973.

${ }^{6}$ D’Ors le dedica al libro cinco "Glosas" muy despectivas en el diario Arriba en febrero de 1949, en las que se esfuerza en intentar desacreditar las tesis de Campo Alange. D’Ors, 1949a; 1949b; 1949c; 1949d; 1949e.

7 Sánchez Camargo, 1963: 28 y 43; Gaya Nuño, 1975: 322.

${ }^{8}$ Barreiro López, 2017: 52.

9 Díaz Sánchez/Llorente Hernández, 2004. Tan solo Begoña Barrera López (2015) y María Inmaculada Alcalá García (2017) han abordado, de forma algo más detallada, esta faceta de Campo Alange.
} 


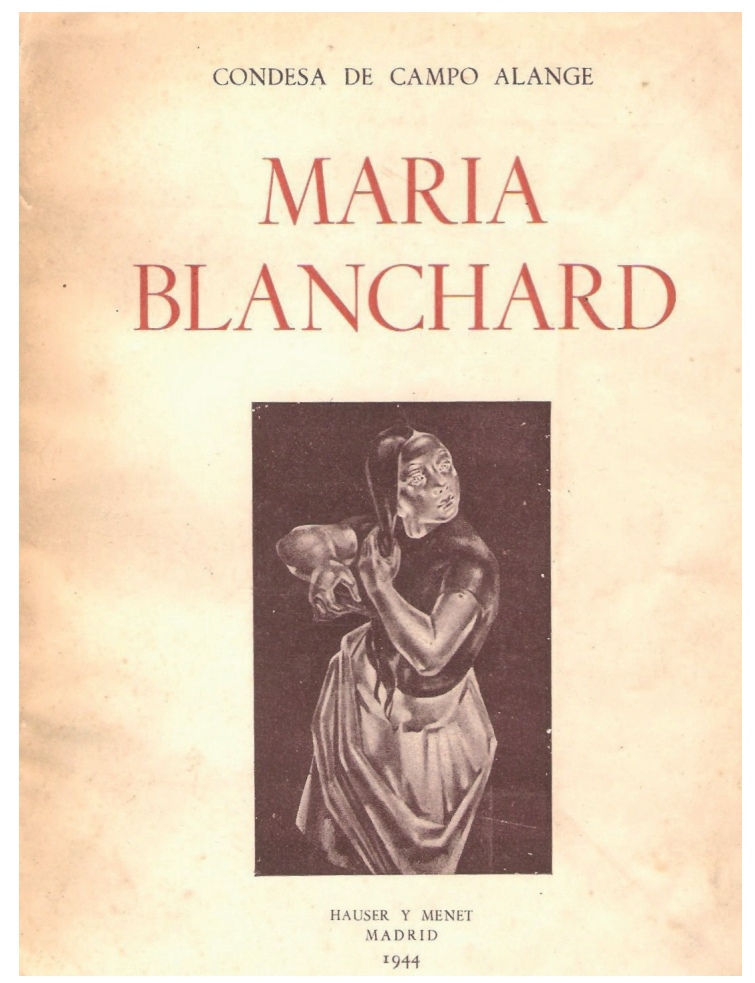

Fig. 1. Portada de María Blanchard, Madrid, Hauser y Menet, 1944.

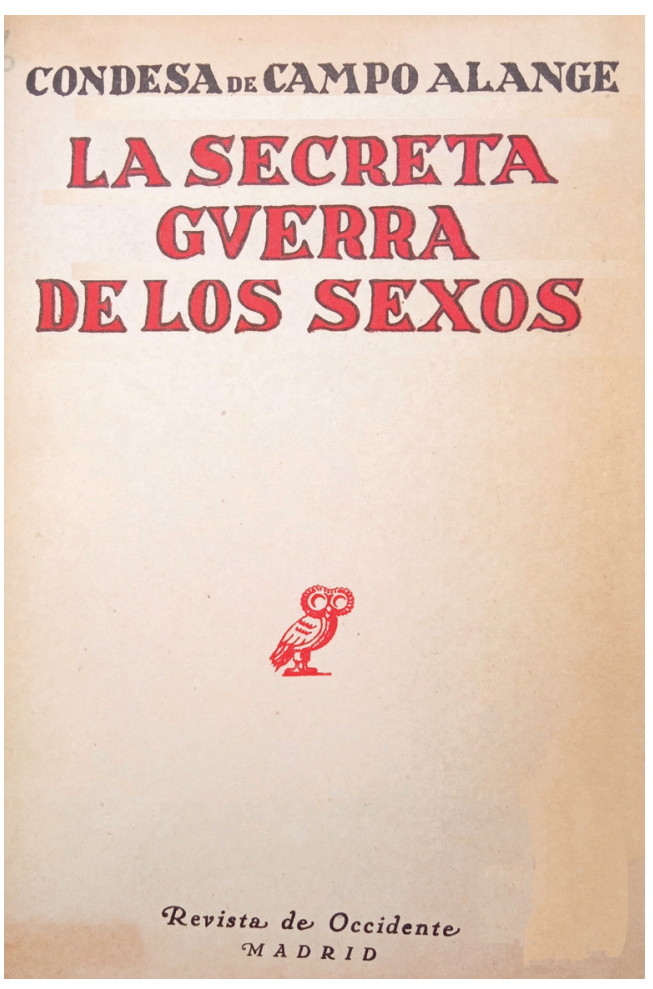

Fig. 2. Portada de La secreta guerra de los sexos, Madrid, Revista de Occidente, 1948.

En definitiva, no solo resulta necesario ahondar en los escritos sobre arte de Campo Alange, sino también desvincular su figura de la ACBA, con la que se ha tendido a identificarla casi exclusivamente. En realidad, lo interesante de la obra de Campo Alange no es tanto lo que la emparenta, cuanto lo que la separa de la crítica de arte de su tiempo. Como apunta Begoña Barrera ${ }^{10}$, sus escritos encajan con dificultad dentro de los tópicos habituales de la crítica española de la época: no comulgó con las concepciones tradicionalistas y nacionalistas del arte que defendía la política artística del franquismo en los cuarenta, no mostró interés por los debates sobre el informalismo en los cincuenta, pero tampoco mantuvo contacto con los críticos de filiación marxista ni participó en las discusiones acerca del realismo como arte político de oposición.

Como intentaré mostrar en este texto, este "pensar fuera del marco" no solo tiene que ver con la singularidad de la trayectoria de Campo Alange, sino también con la fragilidad de su posición como mujer intelectual en el contexto de un régimen, como el franquista, que proscribía, o dificultaba, la participación de las mujeres en la esfera pública. Mantenerse alejada de los "grandes debates" de su tiempo era una forma de labrarse un espacio de libertad, de construirse una voz propia, pero también de iluminar un punto ciego que los críticos hegemónicos (tanto los más próximos al régimen, cuanto los afines al antifranquismo) no fueron capaces de abordar: el lugar de las mujeres dentro del arte moderno. En este sentido (y aun con todas las limitaciones derivadas de la dictadura y de la propia formación autodidacta de la autora), me parece importante subrayar cómo los métodos críticos de Campo Alange anticipan algunos elementos de análisis que la crítica de arte feminista desarrollará mucho más ampliamente a partir de la década de los setenta.

${ }^{10}$ Barrera López, 2014, s.p. 
Un aspecto central de las aportaciones de las llamadas "fundadoras" de la historia y la crítica del arte feminista (como Linda Nochlin o Lea Vergine, por poner tan solo dos ejemplos conocidos) es su voluntad de rescatar del olvido la obra de las mujeres artistas marginadas por el discurso patriarcal. Recordemos, a este respecto, que gran parte de la labor de Campo Alange como crítica de arte se centró en poner en valor el legado artístico de las mujeres. Así, además de su primer texto sobre María Blanchard, consagró una atención especial a otras artistas de sexo femenino, como Carmen Arozena, Liliane Lees-Ranceze o Pepi Sánchez ${ }^{11}$. Junto a este interés por la creatividad femenina, destaca el recurso constante de Campo Alange al método biográfico, desde su primera biografía sobre María Blanchard al estudio biográfico que dedicó en 1973 a Concepción Arenal, pasando por su ambicioso recorrido por la historia contemporánea de las mujeres La mujer en España. Cien años de su historia (1964), donde también introdujo numerosos perfiles biográficos de mujeres destacadas de las artes, las letras o la política españolas ${ }^{12}$. Según ha señalado Mónica Bolufer, la corriente historiográfica que conocemos como historia de las mujeres asumió, desde sus inicios, el reto de recuperar las vidas de las mujeres como alternativa a la historia hegemónica que "que restringía su atención a los hechos políticos y militares, privilegiando a los sujetos masculinos y, en especial, a los 'grandes hombres' (así como algunas, pocas, 'grandes mujeres'), protagonistas de las biografías clásicas. Rescatar esa memoria perdida se presentaba como un proyecto identitario, el de escribir una historia en la que las mujeres del presente pudiesen reconocerse y encontrar antecesoras $[\ldots]^{\prime \prime 13}$.

Para Campo Alange, la biografía fue, en primer lugar, una herramienta de afirmación: frente a la exclusión de las mujeres de los relatos históricos, el género biográfico le permitía poner de relieve sus logros y la calidad de las obras. "Lo que me mueve en este libro es justamente el deseo de divulgar en España la existencia de una mujer genial, compatriota nuestra, cuya obra es admirada hace largos años en el extranjero", escribió, por ejemplo, en el prólogo a María Blanchard ${ }^{14}$. Se entiende así que, en la segunda parte de su libro La mujer en España, en una sección dedicada a las artistas de la primera mitad del siglo XX, Campo Alange insistiese constantemente en subrayar los éxitos profesionales de estas creadoras, dejando de lado, en gran medida, el análisis de las causas por las que habían sido marginadas en las narraciones oficiales de la historia del arte. Además de realizar una semblanza biográfica de cada una de las artistas seleccionadas, la autora sevillana se detenía en enumerar los principales hitos de sus carreras. Así, de Olga Sacharoff destacaba que era una "pintora de indiscutible categoría", que expuso "en Bruselas, Londres, Buenos Aires, Nueva York, Madrid y Barcelona". Sobre Maruja Mallo señalaba que, cuando mostró su obra en la sede de Revista de Occidente, todos creyeron "estar presenciando una auténtica revelación" y que "Federico García Lorca celebró la imaginación y la gracia de la pintora". Mencionaba también a Rosario de Velasco, Ángeles Santos, Delhy Tejero y Marisa Roësset, algunas de las cuales habían sido "premiadas en exposiciones nacionales", cultivando "la disciplina estética con oficio rigurosamente aprendido e indiscutibles aciertos"15.

Si bien, como veremos, en la tercera parte del libro amplió su enfoque, el método adoptado por la autora en esta segunda sección nos sorprende porque parece prestar más atención a la aprobación social cosechada en su época por las artistas que al análisis de sus obras. No obstante, es muy posible que esta toma de postura obedeciese a uno de los objetivos que, en aquel momento, Campo Alange consideraba prioritarios: visibilizar y vindicar las aportaciones de las mujeres artistas, huyendo de un relato victimista. Por otro lado, también hay que tener en cuenta que esta insistencia en los logros profesionales de las creadoras servía para contrarrestar uno de los tópicos que, todavía en los sesenta, rodeaban a la figura de la mujer artista en nuestro país: el del carácter amateur del arte "femenino"16. "Y basta ya de ejemplos -concluía la autora al final de su revisión

\footnotetext{
11 Campo Alange, 1958; 1963a; 1963b.

12 Campo Alange, 1963; 1973.

13 Bolufer, 2014: 90.

14 Campo Alange, 1944: 7.

15 Campo Alange, 1964: 255-258.

16 Sobre este asunto, ver Faxedas/Fontbona/Mayayo, 2019: 229.
} 
de la trayectoria de las artistas de vanguardia en La mujer en España. Una cosa queda probada: la mujer demuestra cada día con mayor frecuencia su capacidad de sentir una fuerte vocación y se dedica plenamente a ella. Sobrepasa la etapa en que cultivaba las artes por 'adorno' y aborda decididamente el profesionalismo" 17 .

Uno de los aspectos más interesantes de la biografía para la historia de las mujeres ha sido el de poder estudiar cómo se entrelazan lo personal y lo colectivo, poniendo de manifiesto que, en los asuntos de la vida privada, tradicionalmente desdeñados, se reflejan muchas veces problemas políticos propios de una época. No se trata, como apunta Bolufer, de "producir explicaciones que, recurriendo a un psicologismo elemental, expliquen las obras y acciones de los sujetos recurriendo siempre a sus conflictos o frustraciones íntimas", sino de entender "cómo la diferencia y la desigualdad entre los sexos ha funcionado históricamente no solo a escala institucional o jurídica, sino también inscribiéndose en las conciencias individuales, modelando afectos y deseos [...]"18. A este respecto, se percibe una evolución en la obra de Campo Alange, desde una visión muy literal de la relación entre vida y obra en su primer texto sobre María Blanchard a una concepción más compleja de la subjetividad, entendida como un proceso históricamente constituido, en sus obras más maduras.

En efecto, su biografía de Blanchard (que data, recordémoslo, de 1944 y que, en muchos aspectos, denota todavía una visión muy tradicional de la mujer) partía de una aproximación psicobiográfica bastante determinista al trabajo de la creadora santanderina: "La obra de María está tan profundamente arraigada en su vida íntima que he creído conveniente exponer lo que fue la causa de su arte" -apuntaba en el prólogo ${ }^{19}$. Para la autora, la trayectoria de Blanchard (a la que se refiere durante todo el libro con expresiones paternalistas que aluden a "la pobre naturaleza" de la pintora, a "su pobre espíritu" o a "su alma maltratada") estuvo marcada por la deformidad con la que nació: ante la imposibilidad de llevar lo que hubiera sido una vida "normal" en una mujer, la pintora decidió concentrar sus energías en su arte ${ }^{20}$.

No obstante, a lo largo de los años, Campo Alange fue refinando sus herramientas de análisis y tomando conciencia de la relevancia del contexto histórico y social para entender las limitaciones a las que se enfrentaron las mujeres artistas. Un ejemplo interesante, a este respecto, lo encontramos en la tercera parte del libro La mujer en España: la autora dedica una sección a analizar el trabajo de sus coetáneas, anticipando, de forma esquemática, algunas ideas que la historiadora estadounidense Linda Nochlin desarrollará en su conocido artículo: "Why Have There Been No Great Women Artists?"21. La escritora sevillana empieza esbozando un breve análisis del marco sociohistórico en el que se desenvuelve la labor de las mujeres creadoras. A su entender, las condiciones materiales concretas que rodean a la creación artística han dificultado especialmente el acceso de las mujeres al ejercicio de la profesión. Si comparamos a las artistas, por ejemplo, con las escritoras, veremos que la incorporación de las mujeres a las artes plásticas ha sido más lenta: "Tal vez se deba a que en la producción pictórica se requiere una habilidad manual, una técnica artesana que exige un largo y continuado esfuerzo, un aprendizaje en escuelas especiales, hoy asimilado a la enseñanza universitaria. Esos años de estudios fuera de casa implican enfrentarse con múltiples problemas económicos y sociales. Tal vez estas causas hayan contribuido a disminuir el número de muchachas que emprendían ese camino"22.

Como luego lo harán las historiadoras feministas, la autora pone de relieve el sesgo patriarcal que ha marcado, históricamente, la práctica del arte: "No olvidemos que el artista no solo expresa su propio sentir, sino el sentir de la colectividad, de la época y de la sociedad en la que vive. La pintura hecha por la mujer ha reflejado siempre no solo su naturaleza y su sentir personal, sino

\footnotetext{
17 Campo Alange, 1964: 258.

18 Bolufer, 2014: 24-25.

19 Campo Alange, 1944: 7.

20 Campo Alange, 1944: 26.

21 Nochlin, 1971: 22-39 у 67-71.

22 Campo Alange, 1964: 335.
} 
también algo de la ideología dominante" ${ }^{23}$. No es extraño así - añade- que las pintoras hayan interiorizado muchos de los prejuicios patriarcales acerca del "arte femenino": en los años cuarenta, "todavía la mujer pinta, salvo excepciones, con bastante timidez. Es como si se sintiese "comprometida' con la sociedad a darle lo que la sociedad exige de ella: ingenuidad, instinto maternal, delicadeza, sensibilidad ..."24.

Hablábamos antes del interés de la corriente de la historia de las mujeres por el género biográfico. Uno de los rasgos más útiles de la biografía para las historiadoras feministas es que nos obliga a cuestionar, de forma muy directa, la falacia de "la objetividad científica". En efecto, si hay algo en lo que ha insistido la teoría feminista es en la idea de que todo saber es un saber situado: el enfoque biográfico, como escribe Bolufer, reviste de este modo la "forma de un vínculo entre dos personas en el que se implica la subjetividad del sujeto que investiga" ${ }^{25}$. Es revelador que, en muchos de sus escritos, Campo Alange rompa con la convención de la voz neutra, tomando la palabra en primera persona y explicitando la relación que la une a las mujeres a las que estudia. En algunos casos, se trata de un vínculo directo, como el que tenía con Carmen Arozena (a la que homenajea evocando toda una serie de recuerdos personales); en otros, se trata de una identificación retrospectiva, como la que le lleva a interesarse por la figura de Concepción Arenal: "Para mí la importancia de Concepción Arenal reside en estar situada en los orígenes de la modernidad, allí donde se inician unos cambios sociales, especialmente para la mujer, que repercuten con fuerza en nuestros días [...] Con Concepción Arenal se inicia en España, en forma embrionaria, claro está, la mujer moderna que da vida por último a la muchacha de hoy"26.

Este vínculo entre el objeto (la biografiada) y el sujeto (la biógrafa) hace que, en ocasiones, en la disciplina de la historia de las mujeres, se entrecrucen la biografía y la autobiografía, como observa Bolufer: "En esos casos, la relación, implícita o explícitamente, se entiende, en última instancia (y a pesar de las diferencias en tiempo y valores), como una complicidad, para la que se utiliza la metáfora de la amistad íntima y que constituye una vía no solo de conocimiento histórico, sino también de autoconocimiento"27. Recordemos, a ese respecto, que además de la biografía, Campo Alange cultivó también el género autobiográfico. Para ella, como explicaba en sus memorias al evocar la escritura de su primer libro, ambos enfoques estaban indisolublemente unidos: "Y es que, en realidad, al tiempo que daba a conocer en España a María Blanchard, yo misma, conocida socialmente, me revelaba como escritora" ${ }^{28}$. Su nacimiento como mujer escritora estuvo ligado así, según el propio relato de Campo Alange, al conocimiento de la obra de otra mujer; el descubrimiento de la pintora santanderina implicó también un autodescubrimiento: "comprendí que el camino que había emprendido era el mío, el auténticamente mío, del que ya no podría apartarme mientras viviera" 29 .

Junto a la reivindicación del lugar de la mujer artista, otra línea de investigación emprendida desde los setenta por las historiadoras feministas ha sido el análisis crítico de las imágenes de mujeres en la historia del arte, en particular en la obra de los "grandes" pintores de sexo masculino. En mi opinión, también en este terreno Campo Alange planteó algunas vías de trabajo que podríamos calificar de protofeministas. En 1958, Camilo José Cela le encargó que pronunciase en el Club Urbis una conferencia sobre el pintor José Gutiérrez Solana; ese mismo año, el texto se publicó, bajo el título de "Solana y la mujer", en la revista Papeles de San Armadans y fue reproducido, tres años más tarde, en el libro La mujer como mito y ser humano ${ }^{30}$. Se trata de un artículo de gran viveza literaria, donde la autora presenta a Solana como un hombre bueno, pero algo tosco, un solitario con tintes misóginos atraído por el dolor, la fealdad y lo grotesco. Para Campo

\footnotetext{
23 Campo Alange, 1964: 336.

24 Campo Alange, 1964: 336.

25 Bolufer, 2014: 105.

26 Campo Alange, 1973: 6.

27 Bolufer, 2014: 106.

28 Campo Alange, 1983: 60.

29 Campo Alange, 1983: 60.

30 Campo Alange, 1961: 61-75.
} 
Alange, las mujeres en la pintura de Solana se dividen en tres grandes categorías: la mujer de carne y hueso, la mujer con máscara y la muñeca. Anticipándose a un conocido artículo de 1973 de la historiadora feminista Carol Duncan, "Virility and Domination in Early twentieth-Century Vanguard Painting" "31, Campo Alange atribuye la aparición de estos tres tipos de imágenes de mujeres en la obra de Solana a una voluntad de dominio patriarcal, ya sea esta consciente o inconsciente: "Solana - como ocurre con tanta frecuencia al hombre - procura dividir a la mujer, desarticularla, sin duda para mejor vencerla. Vencerla en su imaginación y en la vida, fuera y dentro de sí"32. Según la autora, Solana reproduce un tipo de representación binaria de la mujer característica de la cultura patriarcal: en la obra del pintor, se reconoce "la clásica dualidad entre rubias y mujeres, entre la mujer pura y la impura", lo que obedece a "un sistema de autodefensa"33.

Esta última observación es interesante porque revela cómo la escritora sevillana, lectora y admiradora de Sigmund Freud, intuye el uso que hará más tarde la crítica feminista del psicoanálisis. Campo Alange relaciona la representación de la mujer en la obra de Solana con su psicología de soltero irredento y misógino: en la vida del artista madrileño y de su hermano (con el que convivía), "la mujer juega un papel eternamente secundario, si bien indispensable. El pintor no concede a la mujer más papel que el estrictamente necesario en su vida de soltero empedernido"34. Esto explica la predilección de Solana por el motivo de la máscara:

La máscara de las sociedades primitivas, de apariencia horrible, diabólica o semidivina, tuvo muchas veces como finalidad asustar a la mujer para someterla más fácilmente a la tribu, regida por hombres. El mascarón popular y solanesco ridiculiza a la mujer, se burla de ella. El porqué de esta oculta actitud se adivina fácilmente. La mujer, genéricamente, en tanto que poder social, ya no es temible. Está vencida, al menos transitoriamente ${ }^{35}$.

Del mismo modo, para Solana, la muñeca es la expresión de una fantasía masculina. Después de describir los maniquíes que poblaban la casa del pintor, la autora sevillana sugiere la idea de que estos representan, para él, el ideal una feminidad disponible y sumisa: "Las muñecas no mueren, evidentemente, pero tampoco viven y esto es también importante para Solana, porque tampoco aman, ni solicitan ser amadas. Le dejan tranquilo. Están quietas, pasivas, insensibles. A veces, ni siquiera tienen cuerpo. Algunas se mueven, sí, es cierto que le dan la ilusión de la vida, pero él es dueño de regular sus mecanismos" ${ }^{\prime 36}$. Para plasmar más gráficamente este sueño de una feminidad bajo control, en la conferencia pronunciada sobre Solana en el Club Urbis, Campo Alange se llevó una cabeza de maniquí y la colocó en la mesa, donde permaneció durante todo el transcurso de la charla: en una fotografía publicada por el diario $A B C$ [fig. 3], percibimos el contraste, sin duda buscado por la propia autora, entre la solemnidad del entorno (el cortinaje detrás de la conferenciante, el escritorio de caoba frente al que está sentada, el flexo de lectura y el vaso de agua sobre la mesa, el propio aspecto "respetable" de Campo Alange...) y esa presencia incongruente del maniquí, que le otorga un tono humorístico, no exento de crítica, a toda la escena.

Una última vertiente del trabajo de la escritora que la emparenta con la historiografía feminista es la atención que prestó a la reflexión sobre la "diferencia" femenina. La pregunta acerca de la existencia de una presunta sensibilidad artística femenina generó un amplio debate entre las teóricas feministas en los años setenta y ochenta ${ }^{37}$. ¿Existe una "naturaleza femenina" común a todas las mujeres? Y si es así, ¿cómo se traduce esa "feminidad" en el ámbito de la producción artística o literaria? ¿Puede hablarse de un "arte o de una literatura de mujeres" diferente del que producen los hombres? En este terreno, el pensamiento de Campo Alange fue evolucionando desde una po-

\footnotetext{
31 Duncan, 1973: 30-39.

32 Campo Alange, 1961: 67.

33 Campo Alange, 1961: 67.

34 Campo Alange, 1961: 68.

35 Campo Alange, 1961: 72.

${ }^{36}$ Campo Alange, 1961: 74. Cursiva en el original.

37 Ver Mayayo, 2003: 89.
} 


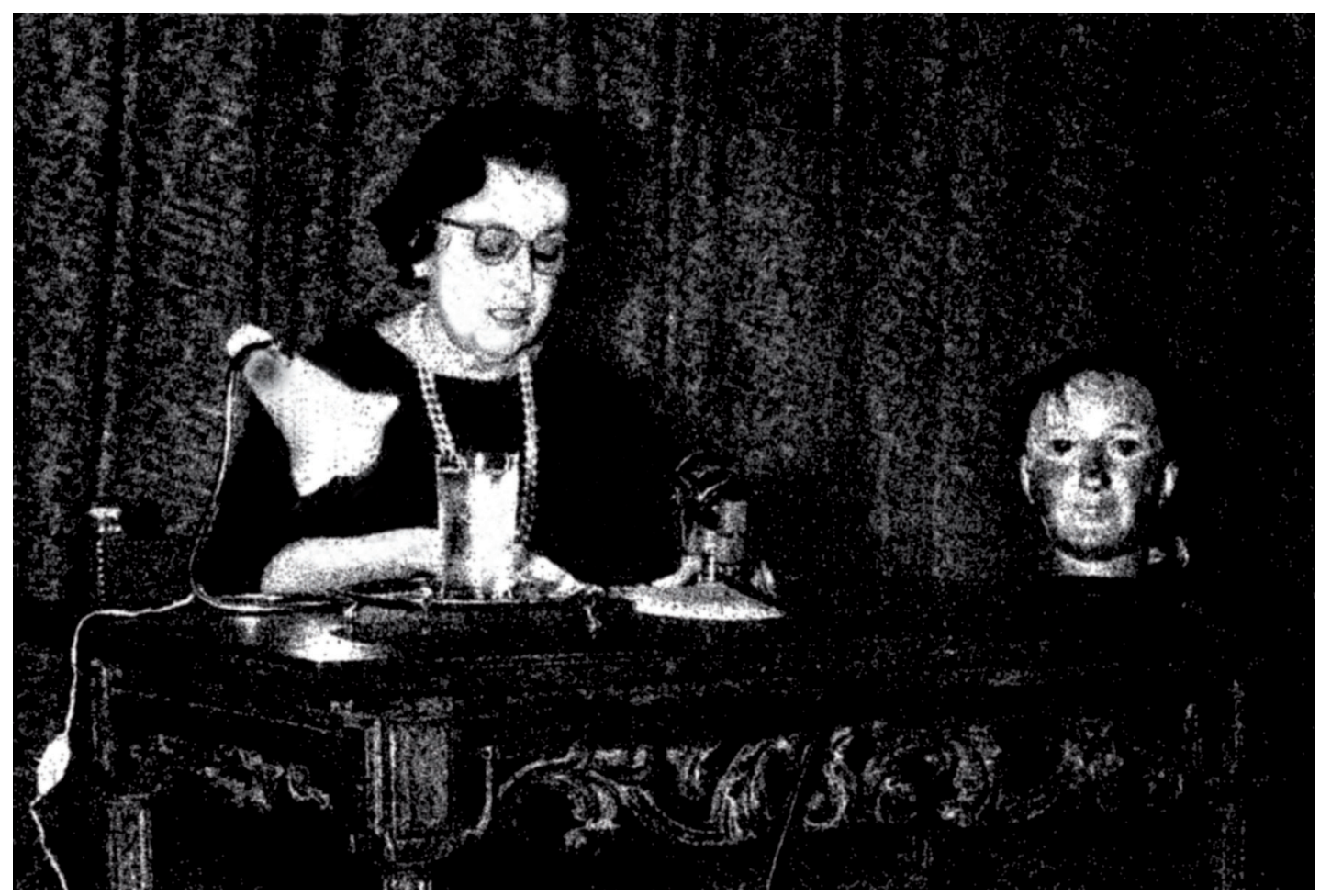

Fig. 3. Conferencia de María Campo Alange en el Club Urbis. Fuente: ABC, 6 de febrero de 1958.

sición conservadora y esencialista en sus primeros textos hasta un enfoque mucho más constructivista en sus obras maduras. En efecto, en su biografía de Blanchard, la autora parecía tener muy claro que la carrera de la pintora santanderina se explicaba por no haber podido llevar la vida que le estaba destinada como mujer: "De no ser por su deformidad, su trayectoria en la vida hubiera sido la normal; el amor, un marido, los hijos...; pero el azar torció, con su cuerpo, su destino, y María, naturaleza rebelde, ha de sacar más tarde, penosamente, de la negrura de su renunciación, su arte magnífico, hecho a la misteriosa luz de sus más tiernos sentimientos" ${ }^{\prime 38}$. Al no haber podido desempeñar la misión "natural" de la mujer, ser madre, Blanchard habría encontrado en el arte un subrogado de esa maternidad frustrada: "mientras que los hombres pintan escenas de los puertos o la vida militar, María, que se ha encontrado por fin a ella misma pintando retratos de niños, juega con los pinceles a la maternidad" 39 .

No obstante, cuando la autora vuelve a este asunto veinte años después, vemos que sus ideas han variado radicalmente. En un texto sobre la pintora Liliane Lees-Ranceze, rechaza de plano esa interpretación esencialista acerca del "arte femenino" que permeaba su libro anterior: "No quiero caer en el tópico de ver en la pintura de Liliane esa sensibilidad 'femenina' que tantos varones creen descubrir en la obra de arte hecha por una mujer" ${ }^{\prime 40}$. Esta voluntad de corregir el sesgo sexista de sus primeras interpretaciones se refleja aún más claramente en el texto que presentó para el catálogo de la exposición de María Blanchard en la Galería Biosca a finales de $1976^{41}$. Como observa Barrera, si bien la autora copió párrafos enteros de su libro del año 44, realizó algunas modificaciones muy significativas:

\footnotetext{
${ }^{38}$ Campo Alange, 1944: 26.

39 Campo Alange, 1944: 58.

${ }^{40}$ Campo Alange, 1963b: s.p.

${ }^{41}$ Campo Alange, 1976: s.p.
} 
Así, si en 1944 había asegurado que "de no ser por su deformidad su trayectoria en la vida hubiera sido la normal" [...], en 1976 rectificaba el sentido de la oración afirmando que "de no ser por su deformidad, la trayectoria de María habría sido la corriente" [...], transformando de este modo su consideración acerca de lo que tendría que ocurrir por otra relativa a lo que suele ocurrir. Desaparecieron asimismo fragmentos enteros, como aquel en el que había declarado que para la mujer "todas sus energías están fijamente enfocadas a la maternidad" [...], y otros párrafos fueron elocuentemente transformados: de la cita de 1944 sobre la creatividad de Blanchard que [...] "quiere brotar sin trabas, lejos de toda teoría, que tan mal va con su talento esencialmente femenino" [...], la escritora eliminó esta última frase en 1976 dejando intacto el resto ${ }^{42}$.

En conclusión, la obra de Campo Alange es un ejemplo de la necesidad de seguir reescribiendo la historia cultural del franquismo para incorporar la aportación de las mujeres. Muchas de ellas - podría decirse- han sido doblemente ignoradas: ignoradas por la corriente historiográfica de la historia intelectual, centrada, por lo general, en debates y referentes masculinos, pero también por las historiadoras del arte feministas, muy influidas por herramientas de análisis de origen anglosajón no siempre útiles para comprender las particularidades de la realidad española. En ese sentido, como lo hacía la propia Campo Alange, es importante pensar fuera del marco: releer la figura de la escritora sevillana como crítica de arte protofeminista es una forma de contribuir a avanzar hacia una historia feminista del arte concebida en términos más globales.

\section{BIBLIOGRAFÍA}

Alcalá García, María Inmaculada (2017): “La voz oculta de María Campo Alange. La escritora en espera”. Tesis doctoral presentada en la Universitat Jaume I. En: http://repositori.uji.es/xmlui/handle/10803/404189 [Consulta: 2 de junio de 2020].

Barrera López, Begoña (2014): "Sobre María Laffitte y la Real Academia Sevillana de Buenas Letras". En: Revista de Humanidades, 21, artículo 2. En: http://www.revistadehumanidades.com/articulos/60-sobre-maria-laffitte-y-la-realacademia-sevillana-de-buenas-letras [Consulta: 5 de mayo de 2020].

Barrera López, Begoña (2015): María Laffitte. Una biografía intelectual. Sevilla: Ed. Universidad de Sevilla.

Barreiro López, Paula (2017): Avant-garde Art and Criticism in Francoist Spain. Liverpool: Liverpool University Press.

Bolufer, Mónica (2014): “Multitudes del Yo: biografía e historia de las mujeres”. En: Ayer, vol. 93, 1, pp. 85-116.

Campo Alange, Condesa de (1944): María Blanchard. Madrid: Hauser y Menet.

Campo Alange, Condesa de (1948): La secreta guerra de los sexos, Madrid: Revista de Occidente.

Campo Alange, Condesa de (1957): Mi niñez y su mundo. Madrid: Castalia.

Campo Alange, Condesa de (1958): La poética ingenuidad de Pepi Sánchez. Madrid: Editora Nacional.

Campo Alange, Condesa de (1959): La flecha y la esponja, Madrid: Arión.

Campo Alange, Condesa de (1961): "Solana y la mujer". En: La mujer como mito y como ser humano. Madrid: Taurus, pp. 61-75.

Campo Alange, Condesa de (1963a): Carmen de Azorena. Madrid: Sala de Exposiciones de la Dirección General de Bellas Artes.

Campo Alange, Condesa de (1963b): Liliane Lees-Ranceze. Madrid: Publicaciones Españolas.

Campo Alange, Condesa de (1964): La mujer en España. Cien años de su historia. Madrid: Aguilar.

Campo Alange, María (1973): Concepción Arenal (1820-1893). Estudio biográfico documental. Madrid: Revista de Occidente.

Campo Alange, María (1976): “María Blanchard”. En: María Blanchard. Madrid: Galería Biosca, 1976, s.p.

Campo Alange, María (1983): Mi atardecer entre dos mundos. Recuerdos y cavilaciones. Barcelona: Planeta.

Díaz Sánchez, Julián / Llorente Hernández, Ángel (2004): La crítica de arte en España (1939-1976). Madrid: Istmo.

D’Ors, Eugenio (1949a): “Glosa”. En: Arriba, 10-XII-1949a, p. 3.

D’Ors, Eugenio (1949b): “Glosa”. En: Arriba, 11-XII-1949b, p. 3

D’Ors, Eugenio (1949c): “Glosa”. En: Arriba, 12-XII-1949c, p. 3.

D’Ors, Eugenio (1949d): “Glosa”. En: Arriba, 13-XII-1949d, p. 3.

D’Ors, Eugenio (1949e): “Glosa”. En: Arriba, 15-XII-1949e, p. 3.

Duncan, Carol (1973): "Virility and Domination in Early 20th-Century Vanguard Painting". En: Artforum, diciembre de 1973, pp. 30-39.

${ }^{42}$ Barrera López, 2015: 178. 
Faxedas, Maria Lluïsa / Fontbona, Isabel / Mayayo, Patricia (2019): "Se Rendre Visible dans 1'Espagne de Franco: le Salón Femenino de Arte Actual (1962-1971)”. En: Artl@s Bulletin, vol. 8, 1, pp. 225-235.

Gaya Nuño, Juan Antonio (1975): Historia de la crítica de arte en España. Madrid: Ibérico Europea de Ediciones.

Mayayo, Patricia (2003): Historias de mujeres, historias del arte. Madrid: Cátedra.

Nochlin, Linda (1971): “Why Have There Been No Great Women Artists?”. En: ARTnews, enero de 1971, pp. 22-39 y 67-71.

Sánchez Camargo, Manuel (1963): Historia de la Academia Breve de Crítica de Arte. Homenaje a Eugenio d'Ors. s.n.

Fecha de recepción: 23-VII-2020

Fecha de aceptación: 25-XI-2020 